\title{
O Uso do Ultra-Som (US) na Reumatologia
}

\section{Ultrasound (US) Use in Rheumatology}

\author{
Ana Beatriz Cordeiro de Azevedo ${ }^{(1)}$, Emiliano Pontes Martins ${ }^{(1)}$, \\ Haroldo Tenório de Holanda ${ }^{(1)}$, Sônia de Aguiar Vilela Mitraud ${ }^{(2)}$, Artur da Rocha Correa Fernandes ${ }^{(3)}$, \\ Rozana Mesquita Ciconelli(4)
}

\section{RESUMO}

Nos últimos anos, a ultra-sonografia tem consolidado o seu papel como importante meio de diagnóstico por imagem na avaliação de doenças com comprometimento do sistema musculoesquelético. O desenvolvimento de novas tecnologias aplicadas na utilização do ultra-som (US), como novos transdutores, softwares e o Doppler, tornou possível a visualização de estruturas intra-articulares e da vascularização sinovial. Atualmente, além de auxiliar no diagnóstico de lesões de partes moles e identificação de coleções líquidas, o ultra-som tem sido empregado na avaliação de estruturas articulares comprometidas por doenças reumáticas e como guia para a realização de procedimentos em reumatologia.

Palavras-chave: ultra-som, reumatologia.

\section{INTRODUÇÃO}

Desde a última década, o ultra-som (US) tem sido cada vez mais utilizado na propedêutica de doenças com comprometimento articular e de tecidos moles, conquistando seu espaço como método de imagem na avaliação e seguimento de doenças reumáticas. Na Europa, o US é bastante utilizado na avaliação das patologias que acometem o sistema musculoesquelético. Nos EUA, no entanto, o US é, relativamente, pouco empregado com este objetivo, devido a maior disponibilidade da ressonância magnética (RM), associada a uma escassez de programas destinados ao treinamento do uso do US com esta finalidade ${ }^{(1)}$.

Os avanços tecnológicos têm levado a um aprimoramento

\begin{abstract}
In the past years, ultrasonographic studies achieved a solid position as an important method of imaging diagnosis in the evaluation of musculoskeletal diseases. Visualization of intra-articular structures and synovial vascular flow improved with the development of new ultrasound technologies, as better transducers, software and Doppler techniques. Ultrasound is being applied as an assistant diagnostic tool in the identification of soft tissue lesions and fluid collections, evaluation of articular structures compromised by rheumatic diseases and also as a guidance tool for invasive procedures in rheumatology, like joint aspiration and injection.
\end{abstract}

Keywords: ultrasound, rheumatology

crescente dos transdutores e softwares e, conseqüentemente, a um desenvolvimento progressivo da aplicabilidade do US como método de diagnóstico por imagem ${ }^{(1)}$. O US, no sistema musculoesquelético, na maioria das vezes, é empregado para a avaliação de partes moles e detecção de coleções líquidas, mas pode ser utilizado para a visualização de outras estruturas, como a cartilagem e superfícies ósseas, e como guia para a realização de aspirações, biópsias e infiltrações. Além disso, o desenvolvimento de novas técnicas associadas ao US, como o Doppler, por exemplo, pode fornecer algumas informações adicionais. O Doppler pode auxiliar fornecendo informações sobre a vascularização dos tecidos e ser útil na investigação de processos inflamatórios ${ }^{(2)}$.

\footnotetext{
* Trabalho realizado no Serviço de Reumatologia da Universidade Federal de São Paulo (UNIFESP). Recebido em 16/11/2004. Aprovado, após revisão, em 28/04/2005

1. Pós-Graduando(a) em Reumatologia pela Universidade Federal de São Paulo (UNIFESP).

2. Médica do Serviço de Diagnóstico por Imagem da Universidade Federal de São Paulo (UNIFESP).

3. Professor Adjunto do Departamento de Diagnóstico por Imagem da Universidade Federal de São Paulo (UNIFESP).

4. Médica Assistente Doutora da Disciplina de Reumatologia da Universidade Federal de São Paulo (UNIFESP).
}

Endereço para correspondência: Ana Beatriz C. Azevedo, Rua Cardoso de Almeida, 457, apto. 144, Bairro Perdizes, São Paulo, CEP 05013-000, SP, Brasil, e-mail: anabiazevedo@hotmail.com 
Associado a estes progressos, o US possui vantagens que contribuem para a sua valorização como método de diagnóstico por imagem na reumatologia. Trata-se de um método acessível, não-invasivo, que não utiliza radiação ionizante, portátil, de custo relativamente baixo e que permite uma avaliação dinâmica das estruturas articulares e tendões aos movimentos $^{(1,2)}$.

No entanto, a qualidade do US depende da utilização de equipamento adequado e da experiência e perícia do examinador. O US é o método de imagem com maior dependência do examinador, sendo essencial um bom conhecimento sobre os princípios do US, técnica de realização e de anatomia ${ }^{(1,2)}$.

\section{O PAPEL DO US NO REUMATISMO EXTRA-ARTICULAR}

As alterações em estruturas extra-articulares, como tendões, músculos, bursas, ligamentos, nervos e cistos sinoviais podem ser bem visualizadas com o US utilizando-se equipamento adequado. Para o estudo de estruturas superficiais, como tendões, ligamentos e pequenas articulações, deve-se empregar transdutores de alta freqüência $(7,5$ a $20 \mathrm{MHz})$. Para a investigação de doenças em articulações maiores e profundas, como o ombro e as coxofemorais, os transdutores de baixa freqüência $(3,5 \mathrm{a} 5 \mathrm{MHz})$ são mais adequados ${ }^{(2)}$. Dentre as estruturas de maior interesse na avaliação de enfermidades reumáticas com comprometimento das estruturas extra-articulares, podemos destacar as seguintes:

\section{LIGAMENTOS}

São estruturas hiperecóicas muito semelhantes aos tendões. Os ligamentos podem ser diferenciados dos tendões por apresentarem fibrilas mais compactas que estes. Ligamentos superficiais, como o talofibular anterior e o colateral ulnar do cotovelo, são estruturas facilmente visualizadas. Já os ligamentos profundos, como o cruzado anterior do joelho, são mais dificeis de serem identificados. O US pode ajudar na avaliação de rupturas parciais ou completas devido a doenças inflamatórias ou traumáticas. No caso de lesões traumáticas, a presença de hematoma dificulta a visualização dos ligamentos extra-articulares ${ }^{(1,3)}$.

\section{Músculos}

São hipoecóicos, circundados por tecido fibroadiposo, septo fibroso e fáscia, que são estruturas hiperecóicas. $\mathrm{O}$ trauma pode levar à ruptura muscular e contusão e, por conseqüência, à formação de hematoma ${ }^{(3)}$.

\section{TENDÕES}

A anatomia normal dos tendões é facilmente visualizada pelo US. A ecogenicidade dos tendões depende da posição do transdutor relativa a eles. Quando o transdutor está perpendicular aos tendões, visualiza-se uma cadeia linear de ecos fibrilares lineares. Quando o transdutor é posicionado obliquamente ao eixo maior dos tendões, evidencia-se um padrão anecóico artefatual por causa da falta de visualização das fibrilas ecogênicas. As fibrilas ecogênicas são as características ultra-sonográficas do septo endotendíneo. A perda da ecotextura fibrilar é sempre um achado anormal. Ela pode variar de um borramento difuso da textura tendínea a aspectos de interrupções fibrilares focais ${ }^{(1,3)}$.

O US pode mostrar evidências de alargamento da bainha tendínea devido a efusão (halo anecóico), sinovite proliferativa (padrão ecóico) ou ambos (padrão misto). Outros aspectos ultra-sonográficos de envolvimento tendíneo incluem irregularidade da margem tendínea, cisto sinovial na bainha tendínea (distensão hipoecóica) e descontinuidade do tendão (lesão tendínea parcial ou completa). Nos casos de ruptura parcial de um tendão, observa-se uma região hipoecóica ou anecóica e, em casos de rupturas completas, pode-se visualizar a solução de contigüidade do tendão ${ }^{(3,4)}$.

Uma das articulações que mais se beneficia do US na avaliação de tendões é o ombro. A possibilidade de comparação do membro sintomático com o contra-lateral assintomático e de avaliação dinâmica, além das outras vantagens do US já citadas anteriormente, tornam este método uma excelente opção para a avaliação das patologias do ombro. No caso de comprometimento do manguito rotador, o US é de grande auxílio na confirmação de processos inflamatórios e traumáticos com ruptura parcial ou completa de tendões (Figura 1) e na investigação de tendinopatias calcificadas.

Diferentes estudos revelaram uma sensibilidade de 90 a 95\% e especificidade de quase $90 \%$ do US para a avaliação de rupturas parciais e totais de tendões do manguito rotador ${ }^{(5)}$. As rupturas do tendão supra-espinhoso ocorrem mais comumente na superfície anterior do tendão e podem ser completas ou incompletas. As rupturas na região inferior do tendão supra-espinhoso geralmente são parciais ${ }^{(6)}$. Rupturas parciais do tendão supra-espinhoso são freqüentemente descritas como áreas hipoecóicas dentro do tendão. À medida que estas lesões aumentam, elas tornam-se mais visíveis. Por sua vez, as rupturas completas são descritas como tendão supra-espinhoso de imagem côncava, ausência da porção externa do tendão e presença de uma região hipoecogênica que se estende ao longo de todo o tendão. 

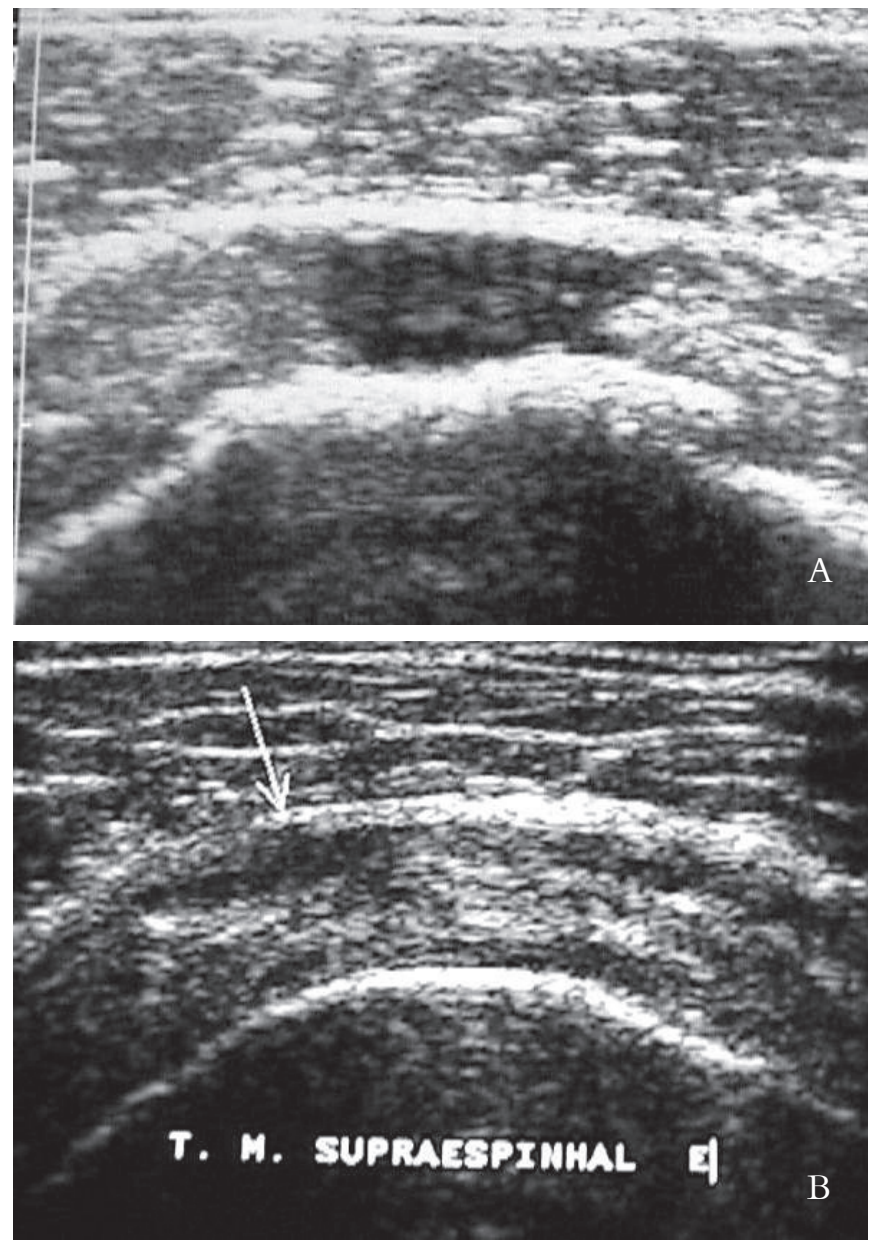

Figura 1 - US de ombro: A - Descontinuidade completa do tendão supra-espinhoso com comunicação da superfície bursal com a articular; B - Irregularidade da superfície bursal do supra-espinhoso caracterizando ruptura parcial

A avaliação do tendão supra-espinhoso em toda a sua extensão, com o posicionamento do transdutor tanto transversalmente quanto sagitalmente ao maior eixo do tendão, é importante para uma adequada avaliação da presença ou não de lesão ${ }^{(5)}$. A presença de líquido na articulação glenoumeral, na bursa subacromial e na bainha do bíceps, a perda do contorno do tendão, pequenas áreas de calcificação (pequenos focos ecogênicos dentro do tendão que projetam uma sombra acústica) e de sinovite (espessamento da cápsula articular) também sugerem que possa haver alguma ruptura de um dos tendões do manguito rotador ${ }^{(6)}$. A tendinite do bíceps (acúmulo de líquido ao seu redor, aumento do seu tamanho e a presença de áreas hipoecogênicas no tendão) geralmente acompanha as patologias que acometem o manguito rotador ${ }^{(6)}$. As rupturas parciais dos tendões do manguito rotador podem ser tratadas clinicamente.
O tratamento cirúrgico das lesões completas permanece controvertido. Nos casos em que ocorrem em pacientes jovens ou ativos a abordagem cirúrgica deve ser realizada o mais precocemente possível. Mas nos casos em que elas ocorrem em idosos ou pacientes menos ativos pode-se tentar um tratamento conservador, inicialmente. Caso não haja melhora significativa em três meses, a intervenção cirúrgica deve ser considerada, sendo a principal indicação para realizá-la a presença de dor intratável ${ }^{(7)}$. A técnica cirúrgica a ser adotada, se por artroscopia ou via aberta, depende do tamanho da ruptura e do grau de retração do tendão acometido(5). A degeneração primária dos tendões que ocorre com a idade é, freqüentemente, indistinguível das rupturas pequenas e parciais dos tendões do manguito rotador. Portanto, deve-se estar atento para a idade do paciente e à clínica para se valorizar corretamente os achados ao US ${ }^{(3)}$.

O US também é especialmente útil na avaliação das tendinites, tenossinovites (Figura 2) e cistos sinoviais em punhos e pequenas articulações das mãos, cisto de Baker e lesões traumáticas ou inflamatórias dos tendões patelares, tendão de Aquiles e outros tendões dos tornozelos e pés ${ }^{(3)}$.
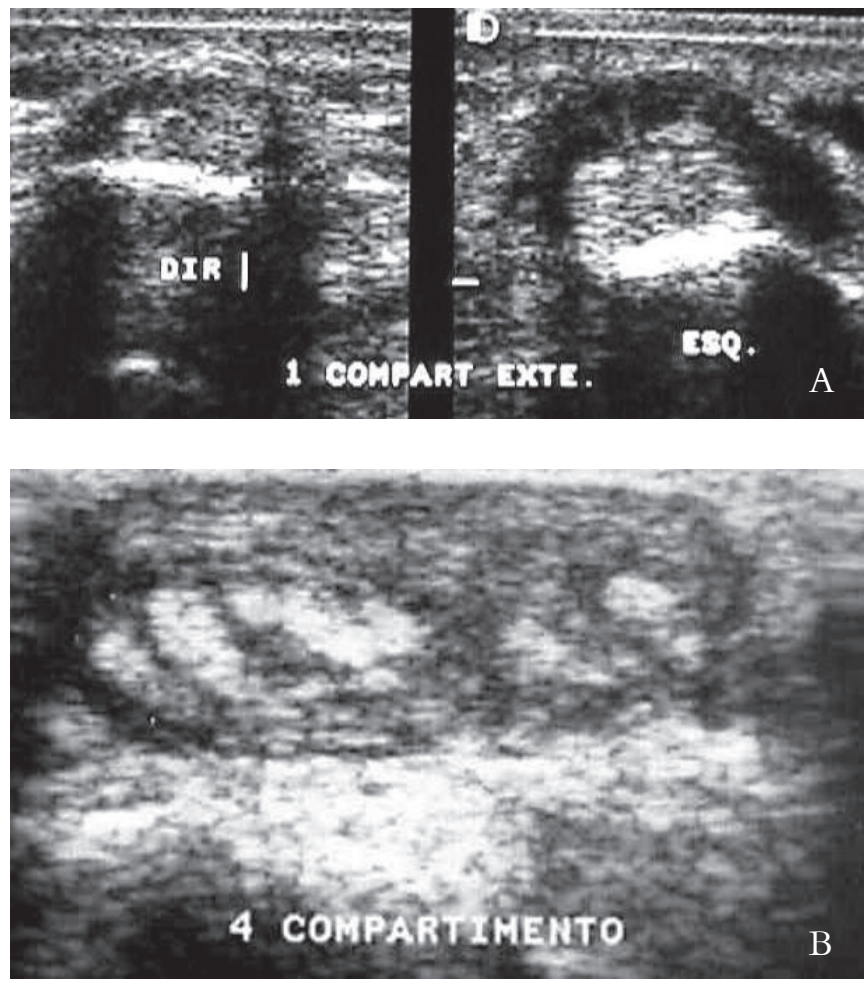

Figura 2 - US de punho: A - Halo hipoecogênico ao redor do tendão do $1^{\circ}$ compartimento dos extensores; B - Espessamento sinovial da bainha dos extensores do $4^{\circ}$ compartimento 


\section{BURSAS}

O envolvimento das bursas em doenças reumáticas é facilmente detectado pelo US.

Um pequeno volume de líquido pode ser detectado, mesmo quando assimétrico ou unilateral, sem necessariamente ser patológico ${ }^{(3)}$.

\section{NeRVOS PERIFÉRICOS}

Um exame ultra-sonográfico executado com cuidado, com transdutores de freqüência mais alta do que $10 \mathrm{MHz}$ pode detalhar os nervos periféricos. Uma aparência fascicular típica (áreas hipoecóicas separadas por bandas hiperecóicas) se correlaciona com a estrutura histológica de nervos periféricos ${ }^{(8)}$.

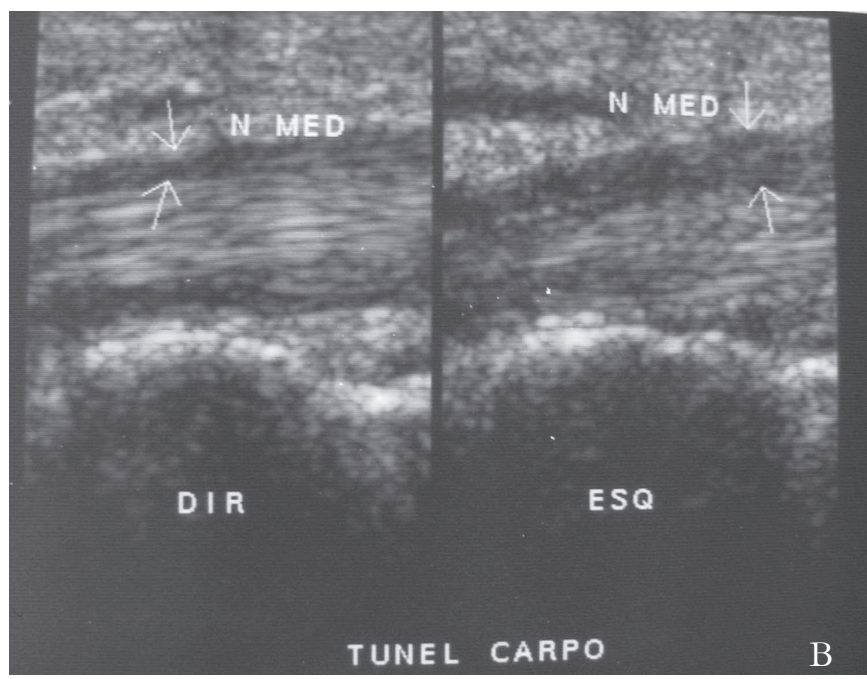

Figura 3 - US de punho: Espessamento do nervo mediano, que se apresenta hipoecogênico difusamente e com área maior que $10 \mathrm{~mm}$

A síndrome do túnel do carpo (STC) é um dos diagnósticos mais freqüentes no dia-a-dia do reumatologista. A STC está associada a várias condições clínicas, como artrite reumatóide, hipotireoidismo, gravidez, entre outros. O US tem se mostrado de grande utilidade na investigação da STC (Figura 3). Um estudo evidenciou que o US é mais específico para o diagnóstico da STC que a eletroneuromiografia (ENMG). US: sensibilidade de 70\% e especificidade de $63 \%$. ENMG: sensibilidade de $98 \%$ e especificidade de $19 \%{ }^{(9)}$.

\section{O PAPEL DO US NO REUMATISMO ARTICULAR}

O US pode revelar alterações em diversas estruturas que compõem a articulação: osso subcondral, cartilagem articular, sinóvia e espaço articular. Dessa forma, podemos encontrar efusão (derrame), proliferação sinovial, calcifi- cações e lesões ósseas, entre outros achados, nas articulações acometidas em doenças reumáticas. O US pode ser aplicado na propedêutica de grandes articulações como joelhos e quadris bem como, graças ao desenvolvimento de transdutores de alta freqüência, no estudo intra-articular de pequenas articulações como as metacarpofalangianas (MCP), as metatarsofalangianas (MTF) e as interfalangianas (IF) dos pés e das mãos ${ }^{(2)}$.

O derrame sinovial é um achado precoce em doenças articulares inflamatórias, além de ser o achado sonográfico mais comumente encontrado em pacientes com artrite. À ultra-sonografia, o derrame sinovial caracteriza-se por um aumento do espaço articular, onde se evidencia uma área anecóica, hipoecogênica e com bordos bem definidos. Essa alteração pode estar acompanhada pela presença de áreas ecóicas que correspondem à proliferação sinovial ou à presença de material proteináceo livre no espaço articular (Figura 4). O exame dinâmico dessa mesma articulação permite a diferenciação entre essas duas possibilidades, uma vez que a movimentação da junta acometida não modifica as características ultra-sonográficas encontradas na proliferação sinovial, ou seja, corresponde apenas à movimentação das áreas anecóicas e não das áreas ecóicas, correspondentes à proliferação sinovial ${ }^{(10)}$. Dessa forma, o US é de grande valia na avaliação da presença de derrame articular, principalmente em articulações profundas como as coxofemorais. Além disso, o US auxilia na estimativa da quantidade de líquido presente e pode orientar a realização de procedimentos diagnósticos e terapêuticos nestas articulações. A presença de derrame articular nas coxofemorais pode ser secundária a processos inflamatórios, traumáticos ou infecciosos. O US também é útil para a avaliação da presença de sangramento intra-articular no quadril em pacientes hemofílicos, auxiliando na diferenciação entre hemartrose, hemorragia intraperitoneal, sangramento subperiosteal, hemorragia em tecidos moles em torno da articulação do quadril e de hematoma no psoas $^{(11)}$.

Embora o US não seja o método de eleição para a avaliação de sacroilíacas, existem alguns trabalhos que apontam uma perspectiva de sua aplicação junto com o Doppler para a investigação e melhor compreensão dos quadros de dor pélvica durante a gravidez, uma vez que o envolvimento das articulações sacroilíacas nestes casos ainda está para ser esclarecido ${ }^{(12,13,14)}$.

A cartilagem articular também pode ser examinada nas diversas articulações, como joelhos, quadris, ombros, cotovelos e MCP. A cartilagem normal geralmente aparece como uma faixa anecóica entre o osso subcondral e os tecidos moles articulares sobrejacentes, com bordos interiores e exteriores bem definidos. 


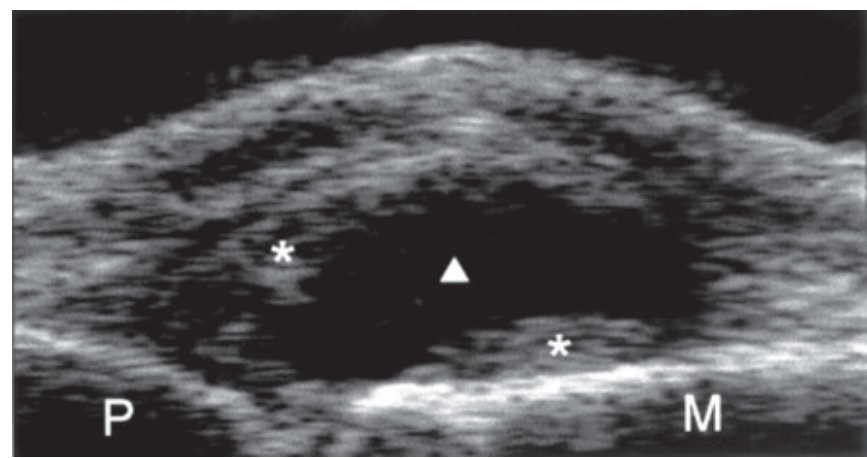

Figura 4 - US MCF (imagem dorso-longitudinal):

$\triangle$ = Fluido sinovial

* $=$ Proliferação sinovial

$\mathrm{P}=$ Falange proximal

M= Osso metacárpico

As características ultra-sonográficas da cartilagem articular na osteoartrose incluem perda da transparência da faixa cartilaginosa, imprecisão na delimitação dos bordos cartilagíneos e, por último, diminuição do espaço articular (Figura 5). Alterações na ecogenicidade da cartilagem podem ser encontradas em associação com alterações características da condrocalcinose. Nesse caso, calcificações cartilaginosas aparecem como uma faixa ecóica sem formação de sombra acústica. Embora o valor do US na avaliação da cartilagem articular ainda precise ser determinado, um estudo recente sugere que este método pode ser útil para o diagnóstico inicial das lesões degenerativas encontradas na osteoartrose ${ }^{(15)}$.

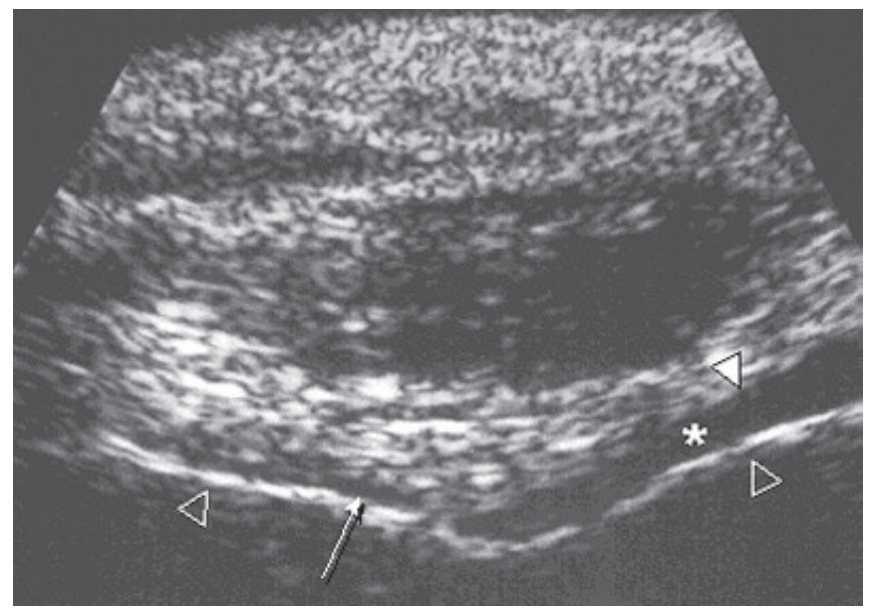

Figura 5 - US joelho (imagem transversal):

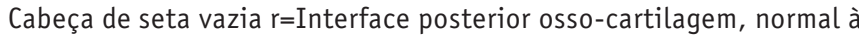
direita e mostrando aumento de intensidade à esquerda (osteoartrose) Cabeça de seta cheia $\mathrm{p}=$ Interface cartilagem-tecidos moles normal à direita * $=$ Cartilagem normal (hipoanecóica) à direita

\#= Afilamento da camada hipoanecóica correspondente à cartilagem hialina à esquerda (osteoartrose)
Alguns estudos têm destacado o papel da ultra-sonografia intra-articular no diagnóstico precoce de erosões ósseas em doença articular de início recente. As erosões ósseas ocorrem como conseqüência de inflamação intraarticular persistente e são caracterizadas por irregularidades na superfície do osso subcondral, conferindo um pior prognóstico aos pacientes que as apresentem. Atualmente, como na maioria das vezes, usa-se o método convencional de raios X para o seu diagnóstico. Essas erosões são detectadas tardiamente. Por outro lado, erosões ósseas podem ser facilmente detectadas através do exame de RN, embora se trate de um método de alto custo e de baixa disponibilidade. Wakefield et al ${ }^{(16)}$, em 2000, e Skudlarek et al, em 2004, estudando pacientes com artrite reumatóide (AR) demonstraram que o US é uma técnica mais sensível que a radiografia convencional na detecção de erosões ósseas precoces. Os achados ultra-sonográficos correspondentes a erosões ósseas que, na maioria das vezes, não foram visualizadas ao raio $\mathrm{X}$ convencional e co-relacionaramse às alterações encontradas no exame de RM, realizado como controle positivo para esses achados. Esses autores sugerem que a ultra-sonografia articular é um método que pode vir a influenciar o tratamento e, conseqüentemente, o prognóstico de pacientes com doença articular de início recente (Figura 6$)^{(16,17)}$.

$\mathrm{O}$ advento de novas tecnologias associadas ao US propiciou o aparecimento de soluções para questionamentos clínicos comuns na prática reumatológica. Entre essas dúvidas podemos destacar a difícil distinção entre espessamento residual e atividade de doença quando do exame de articulações que apresentem aumento crônico do seu volume. O desenvolvimento da técnica de ultra-sonografia de alta resolução, que emprega transdutores multidimensionais de elevada sensibilidade, permitiu uma melhor visualização espacial das estruturas intra-articulares, inclusive da microvasculatura sinovial acometida. A partir disso, alguns autores têm relatado associação entre a extensão da vascularização sinovial, avaliada através do US de alta resolução, e o grau de atividade da doença, em pacientes com $A R^{(18,19)}$. Todavia, alguns relatos foram conflitantes no que diz respeito à interpretação correta de achados ecográficos de inflamação e como diferenciá-los de artefatos gerados a partir do uso dessa tecnologia, a qual caracteriza-se por ser extremamente sensível. Recentemente, o desenvolvimento da técnica de Power Doppler Sonography (PDS) permitiu a nítida visualização do fluxo sanguíneo de baixa velocidade encontrado na microvasculatura sinovial, com diminuição da geração de artefatos de imagem em comparação ao US de alta resolução. 

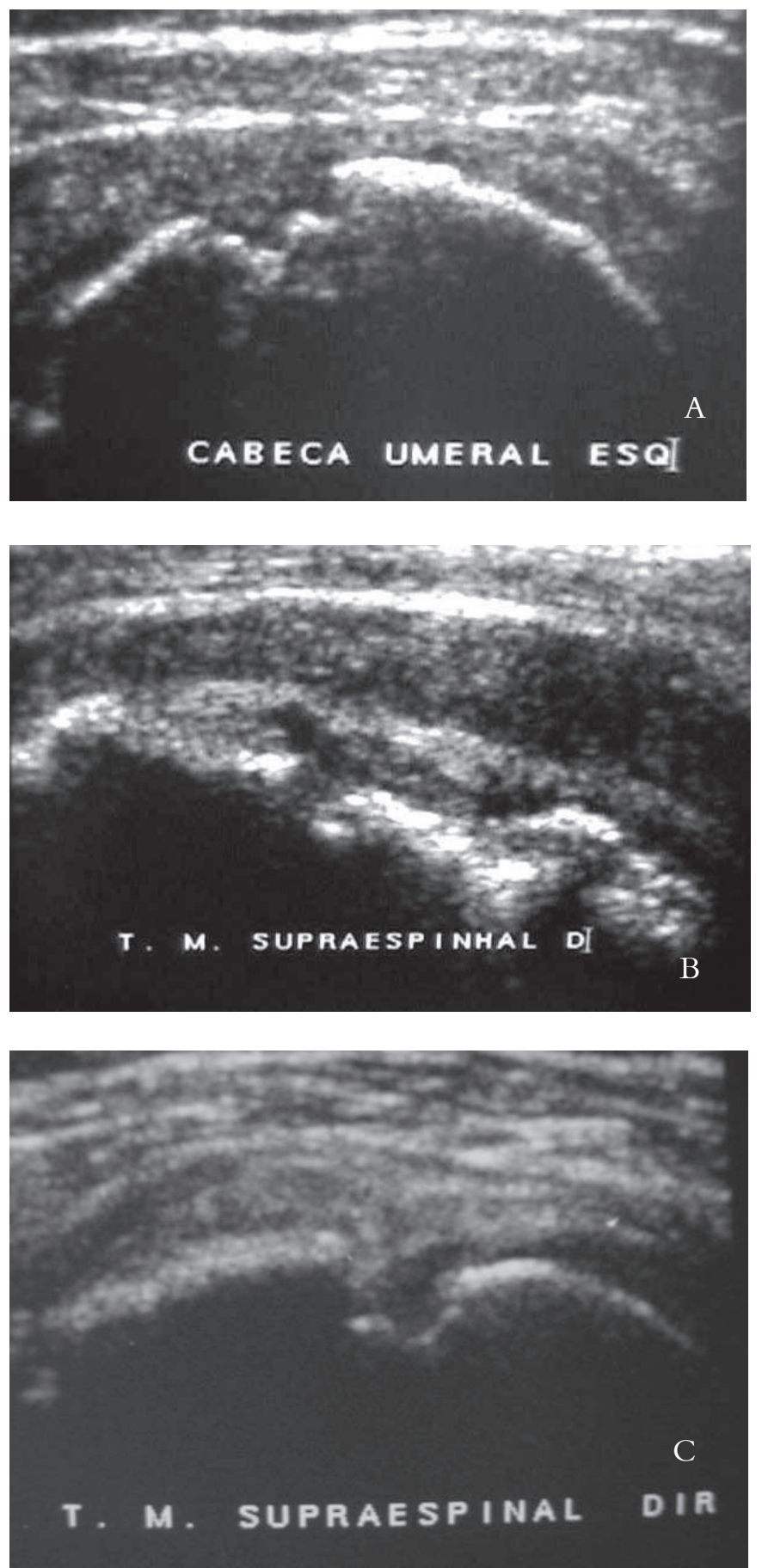

Figura 6 - US de ombro: Irregularidade da cartilagem articular focal na cabeça do úmero compatível com cisto subcondral (A) e irregularidade com importante afilamento difuso e sinovite na cabeça do úmero com lesão do manguito rotador em paciente com $A R(B$ e $C)$

Além da visualização de vasos de pequeno calibre $(<1 \mathrm{~mm})$, essa técnica permite a avaliação da arquitetura desses vasos, o que não era possível com a técnica de Doppler colorido convencional, a qual é adequada para demonstrar fluxos de alta velocidade, presentes em vasos de maior calibre. Em 2001, Walther et a $\left(^{(20)}\right.$ demonstraram que os achados de fluxo sanguíneo sinovial avaliados mediante a técnica PDS correlacionaram-se com a extensão da vascularização encontrada nos achados histológicos de tecido sinovial de joelho, oriunda de pacientes com osteoartrose ou AR, submetidos à artroplastia. Essa correlação positiva provou que a técnica PDS é fidedigna no que concerne à graduação qualitativa da microvasculatura do tecido sinovial ${ }^{(20)}$. Ademais, Klauser et al ${ }^{(21)}$, em 2002, utilizando o Doppler colorido convencional ou o PDS combinado a um contraste de microbolhas super-refletoras de vibrações ultra-sônicas, demonstraram um aumento significativo na detecção da vascularização intraarticular nas juntas dos quirodáctilos de pacientes com AR, em comparação ao uso de ambas as técnicas sem contraste. Os autores sugerem que o uso desse tipo de contraste poderia ser uma forma de aperfeiçoamento das técnicas acima descritas, embora o uso do mesmo ainda seja muito dispendioso, nos dias de hoje ${ }^{(21)}$. Outros autores, utilizando o US de alta resolução, em um estudo preliminar com cinco pacientes com AR, detectaram uma diminuição importante na vascularização sinovial das articulações dos quirodáctilos desses pacientes, após um mês de uso de terapia anti-TNF- $\alpha$, em comparação aos achados encontrados nos mesmos pacientes, anteriormente ao uso dessa modalidade terapêutica ${ }^{(22)}$.

Conclui-se, portanto, que o US tem ampla utilidade no estudo das alterações das diversas estruturas que compõem a articulação (osso subcondral, cartilagem articular, espaço articular, sinóvia). Essa técnica, quando associada a outras tecnologias, permite o estudo funcional das mesmas articulações, com provável utilidade na monitorização clínica de pacientes com acometimento intra-articular de doenças reumáticas.

\section{O PAPEL DO US EM PROCEDIMENTOS NA REUMATOLOGIA}

A tomografia computadorizada (TC) e a fluoroscopia são métodos tradicionalmente utilizados como guias na realização de procedimentos no sistema musculoesquelético ${ }^{(23)}$. O ultra-som é, atualmente, um método alternativo no desenvolvimento de tal prática. Além de permitir a avaliação de partes moles, verificação de líquido intra-articular e avaliação de estruturas articulares, o US pode também orientar e monitorizar punções, biópsias e infiltrações (Figura 7) ${ }^{(2,}$ ${ }^{23-24)}$. A comparação entre estes três métodos revela algumas vantagens do US em relação aos outros dois. A fluoroscopia 
é um método com limitações quando a enfermidade em avaliação se restringe às partes moles. A TC, por sua vez, não permite a realização do procedimento em tempo real, utiliza uma alta dose de radiação e despende um tempo maior que a fluoroscopia para a realização da intervenção. Sendo assim, o US surge como uma alternativa, constitui um método que não utiliza irradiação ionizante, de baixo custo quando comparado aos outros, e portátil, possibilitando a realização de procedimentos à beira do leito em tempo real, o que, conseqüentemente, implica numa menor incidência de complicações ${ }^{(23)}$.

Aspirações, infiltrações e biópsias podem ser guiadas pelo US empregando-se uma das seguintes técnicas: uma em que se marca a pele e a outra sob visão direta $^{(24)}$.

Técnica 1: Utiliza-se o ultra-som para o exame da região a ser abordada e escolhe-se o melhor ponto para realizar a intervenção. O ponto médio do transdutor representa o ponto central da imagem do ultra-som na tela. Após a definição do melhor ponto para a abordagem, o examinador marca na pele do paciente este ponto escolhido. Conforme a profundidade do local a ser abordado, faz-se a escolha da agulha com tamanho apropriado. Após o exame de US, procede-se a assepsia da pele e insere-se a agulha num ponto próximo a marca feita na pele com a mesma direção do transdutor.

Apesar de não permitir a realização do procedimento por visão direta, esta técnica dispensa o uso de revestimento estéril para o transdutor e de gel estéril ${ }^{(24)}$.

Técnica 2: Após a assepsia da pele, realiza-se o exame de US com o transdutor revestido por material estéril, utilizando um gel estéril, ou solução de povidine como alternativa. A introdução e movimentação da agulha são monitorizadas sob visão direta durante todo o procedimento. Quando a agulha é introduzida seguindo um plano longitudinal ao transdutor, ela é visualizada como uma linha ecóica brilhante. No caso da agulha ser introduzida transversalmente ao transdutor, a agulha será visualizada como um ponto brilhante e ecóico. A localização da agulha no espaço intra-articular é fácil e não importa o seu tamanho. Esta técnica é particularmente interessante para intervenções em articulações das mãos, síndrome do túnel do carpo, intervenções em tendões e cistos ${ }^{(24)}$.

O US tem sido progressivamente incorporado na rotina da realização de procedimentos reumatológicos pelas vantagens que oferece, já citadas anteriormente. No entanto, ainda há uma carência de estudos destinados à avaliação do uso sistemático do US em procedimentos no sistema musculoesquelético, diferente do que ocorre em outras circunstâncias, como, por exemplo, para a avaliação de patologias abdominais, da mama e da próstata.
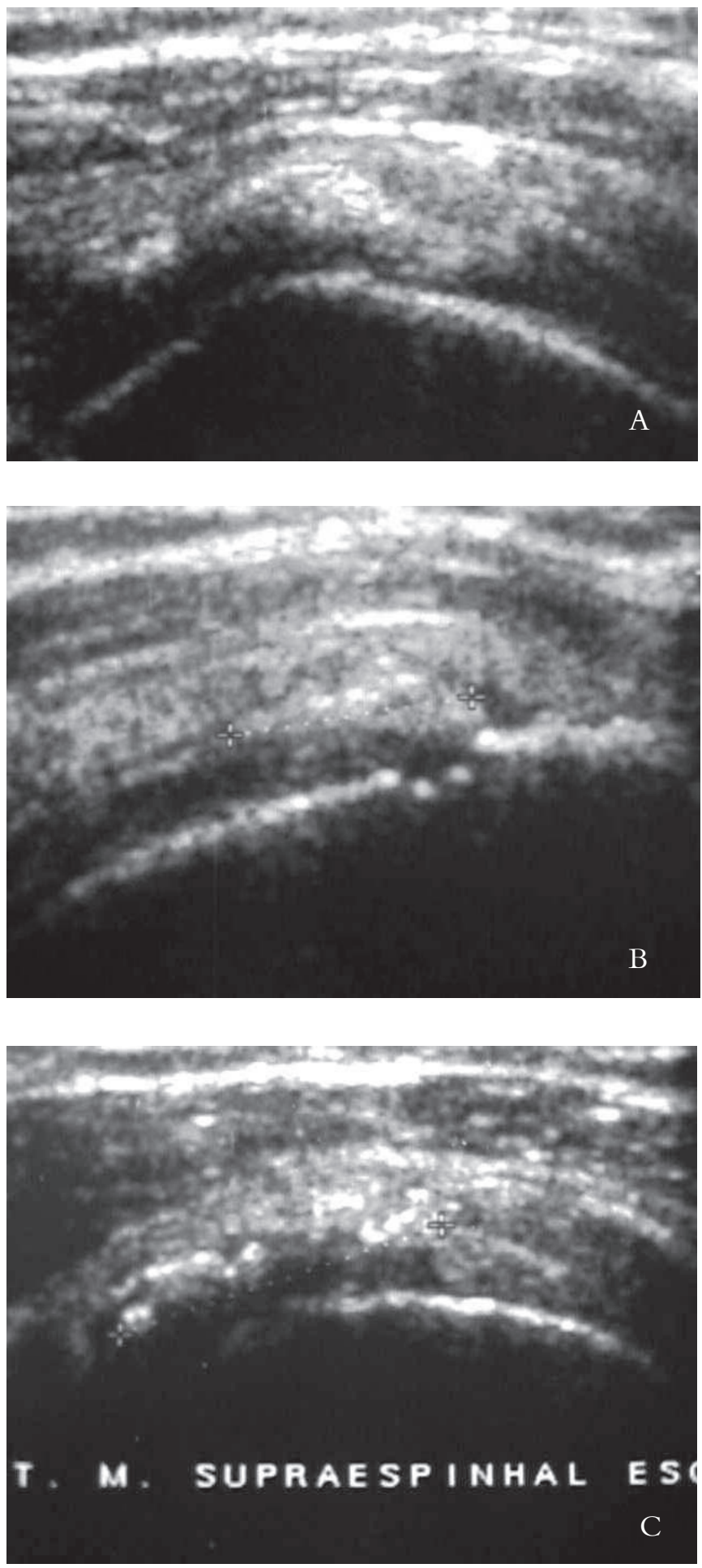

Figura 7 - Procedimento de perfuração de calcificação no supra-espinhoso guiado por US: A - 0 US mostra imagem ecogênica com leve sombra acústica posterior (pré-intervenção), com uma agulha fina e sob o controle do US faz-se várias perfurações na calcificação; $B$ - 0 resultado, sete meses após o procedimento, é uma redução das dimensões da calcificação; C - Um ano após o procedimento, houve acentuada melhora do quadro clínico 
Há também necessidade da realização de estudos comparativos entre os diferentes métodos de imagem empregados como guia para a realização destes procedimentos.

Sofka et al ${ }^{(23)}$ verificaram, através de um estudo retrospectivo, que 165 de 180 procedimentos invasivos no sistema musculoesquelético, realizados no Hospital for Special Surgery de Nova York, foram guiados por US. Dentre os procedimentos realizados, são citados aspirações e infiltrações intra-articulares, infiltrações em tendões, neuroma de Morton, fasciíte plantar, cistos sinoviais, biópsia muscular e de lesões císticas em sinóvias, com uma incidência baixa de complicações, não significativas ${ }^{(23)}$.

Um estudo prospectivo destinado a avaliar o US como método de imagem para guiar a realização de biópsias de tumores no sistema musculoesquelético revelou uma acurácia de 97\%, sensibilidade de 96\%, especificidade de $100 \%$ e valores preditivos positivo e negativo de 100 e 95\%, respectivamente, para tumores de partes moles ou porção extra-óssea de tumores ósseos maiores ou iguais a $2 \mathrm{~cm}$ no esqueleto apendicular, com correlação

\section{REFERÊNCIAS}

1. Lin J, Fessell DP, Jacobson JA, Weadock WJ, Hayes CW: An Illustrated tutorial of musculoskeletal sonography: Part I, Introduction and general principles. AJR 175: 637-645, 2000.

2. Backhaus M, Burmester G-R, Gerber T et al: Guidelines for musloskeletal ultrasound in rheumatology. Ann Rheum Dis 60: 641-9, 2001.

3. Bücklein W, Vollert K, Wohlgemuth A, Bohndorf K: Ultrasonography of acute musculoskeletal disease. Eur Radiol 10: 290-296, 2000.

4. Kubo K, Kanehisa H, Fukunaga T: Gender diferences in the viscoelastic properties of tendon structures. Eur J Appl Physiol 88: 520-526, 2003.

5. Ferri M, Finlay K, Popowich P, Stamp G, Shuringa P, Friedman L. Sonography of full thickness supraspinatus tears: comparison of patient positioning technique with surgical correlation. AJR 184: 180-184, 2005.

6. Allen GM, Wilson DJ. Ultrasound of the shoulder. Eur J Ultrasound. 14: 3-9, 2001.

7. Dalton SE. The soulder. In Hochberg M, Silman AJ, Smolen JS, Weinblatt ME, Weisman MH (Editors): Rheumatology 3rd edition, Mosby, London: 45-54, 2003.

8. Silvestri E, Martinoli C, Derchi LE, Bertolo M, Chiaramondia M, Rosemberg I: Echotexture of peripheral nerves: correlation between US and histologic findings and criteria to differentiate tendons. Radiology 197: 291-296, 1995.

9. Swen WAA, Jacobs JWG, Bussemaker FEAM, Waard J-WD, Bijlsma JWJ: Carpal tunnel sonography by the rheumatologist versus nerve conduction study by the neurologist. J Rheumatol 28: 62-69, 2001.

10. Grassi W, Lamanna G, Farina A, Cervini C: Synovitis of small joints: sonographic guided diagnostic and therapeutic approach. Ann Rheum Dis 58: 595-7, 1999. com outros métodos de imagem (TC e RM), estudo anatomopatológico e/ou evolução clínica. Este mesmo estudo considerou o método de US limitado para a avaliação de tumores císticos, mixóides, tumores cartilaginosos e de lesões localizadas no esqueleto axial ${ }^{(25)}$.

Jones et al ${ }^{(26)}$ observaram, num estudo destinado a avaliar a acurácia de injeções intra-articulares às cegas, utilizando contraste associado ao corticosteróide, para uma avaliação pós-infiltração, que somente 56 de 108 infiltrações foram realmente intra-articulares. Aliada a esta observação, outros autores têm demonstrado que a infiltração de corticosteróide em tendões foi associada a sua degeneração e ruptura ${ }^{(26)}$.

Baseado nestas informações, tem sido incentivada a realização de procedimentos invasivos em reumatologia com o auxílio do US. No entanto, é importante ressaltar que o US é um método examinador-dependente, sendo necessário que aquele que se proponha a utilizá-lo seja um profissional treinado no método, para que realmente possa tirar benefício das vantagens que o mesmo proporciona.

11. Graif M. Ultrasound of the hip. Eur J Radiol 14: 35-43, 2001.

12. Buyruk HM, Snijders CJ, Vleeming A, Laméris JS, Holland WPJ, Stam HJ. The measurements the sacroiliac joint stiffness with colour Doppler imaging: a study on health subjects. Eur J Radiol 21: 117121, 1995.

13. Buyruk HM, Stam HJ, Snijders CJ, Vleeming A, Laméris JS, Holland WPJ. The use of color Doppler imaging for the assessment of sacroiliac joint stiffness: a study of embalmed human pelvises. Eur J Radiol 21: 112-116, 1995.

14. Darnen L, Buyruk HM, Güler-Uysal F, Lotgering FK, Snijders CJ, Stam HJ. The prognostic value of asymmetric laxity of the sacroiliac joints in pregnancy pelvic-related pain. Spine 27: 2820-2824, 2002.

15. Grassi W, Lamanna G, Farina A, Cervini C: Sonographic imaging of normal and osteoarthritic cartilage. Semin Arthritis Rheum 28: 398-403, 1999.

16. Wakefield RJ, Gibbon WW, Conaghan PG et al: The value of sonography in the detection of bone erosions in patients with rheumatoid arthtitis. Arthritis Rheum 43: 2762-70, 2000.

17. Szkudlarek M, Narvestad E, Klarlund M et al: Ultrassonography of the metatarsophalangeal joints in rheumatoid arthritis. Comparision with magnetic resonance imaging, conventional radiography, and clinical examination, Arthritis Rheum 50: 2103-2112, 2004.

18. Weidekamm C, Köller M, Weber M, Kainberger F. Diagnostic value of high-resolution B-mode and Doppler sonography for imaging of hand and finger joints in rheumatoid arthritis. Arthritis Rheum 48: 325-333, 2003.

19. Hau M, Schultz H, Tony H-P et al: Evaluation of pannus and vascularization of the metacarpophalangeal and proximal interphalangeal joints in rheumatoid arthritis by high-resolution ultrasound (multidimensional linear array). Arthritis Rheum 42: 2303-8, 1999.

20. Walther M, Harms H, Krenn V, Radke S, Faehndrich T-P, Gohlke F: Correlation of power Doppler sonography with vascularity of the 
tissue of the knee joint in patients with osteoarthritis and rheumatoid arthritis. Arthritis Rheum 44: 331-8, 2001.

21. Klauser A, Frauscher F, Schrimer M, et al: The value of contrastenhanced color Doppler ultrasound in the detection of vascularization of finger joints in patients with rheumatoid arthritis. Arthritis Rheum 46: 647-53, 2002.

22. Hau M, Kneitz C, Tony H-P, Keberle M, Jahns R, Jenett M: High resolution ultrasound detects a decrease in pannus vascularisation of small finger joints in patients with rheumatoid arthritis receiving treatment with soluble tumor necrosis factor receptor (etarnecept). Ann Rheum Dis 61:55-8, 2002.
23. Sofka CM, Collins AJ, Adler RS: Use of ultrasonographic guidance in interventional musculoskeletal procedures. A review from a single institution. J Ultrasound Med 20: 21-26, 2001.

24. Koski J M: Ultrasound guided injections in rheumatology. J Rheumatol 27: 2131-2138, 2000.

25. Torriani M, Etchebehere M, Amstalden MSc, Amstalden EMI: Sonographically guided core needle biopsy of bone and soft tissue tumors. J Ultrasound Med 21: 275-281, 2002.

26. Jones A, Regan M, Ledingham J, Patrick M, Manhire A, Doherty $\mathrm{M}$ : Importance of placement of intra-articular steroid injections. BMJ 307: 1329-1330, 1993. 